\title{
الوساطة الجزائية في التشريع الجزائري
}

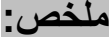

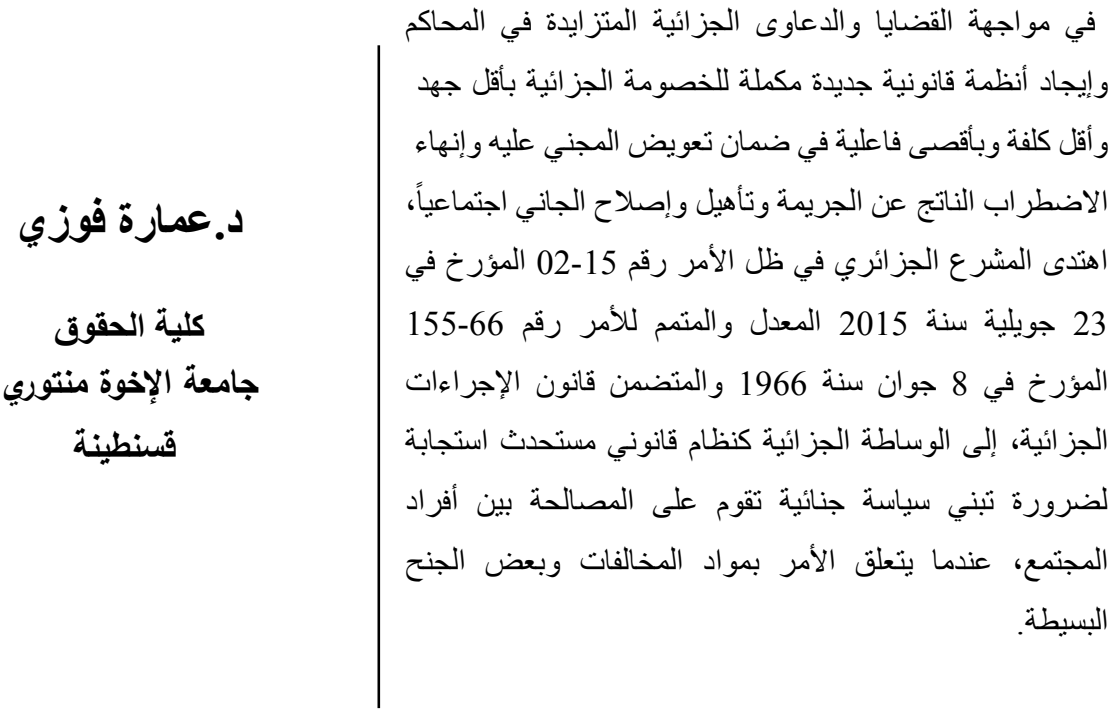

\section{مقدمة: Abstract : \\ ف In front of a relative failure of the}

على القانون الجزائري، فإنها ليست كذللك على مجتمعنا الإسلامي العربي و القبلي، فلفظ الوساطة لا يعد لفظاً

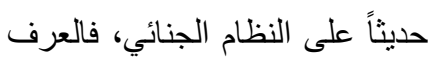
و التنظيم الاجتماعي في القيائل القديمة يوضح لنا أن الوساطة قديمة

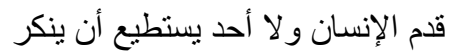

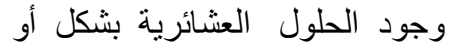
آخر، وإن تفاوتت نسبة قوتها أو اول ضعفها بحسب نطور المجتمع. jurisdictional classic response in the treatment of small and medium delinquency, international and national orientation of contemporary criminal policy opened the way for the gradual introduction of penal mediation among the possible responses to certain offenders lines. Penal mediation remains a relevant measure in respect of both the victim and the perpetrator, legally as socially. 
فالقانون الجنائي العرفي إن صح التعبير ماز ال يحكم الحياة الإجتماعية في الكثير من المناطق العثائرية

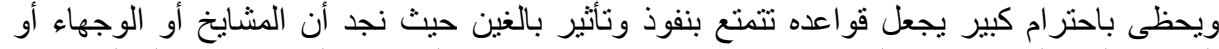

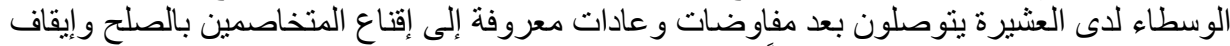

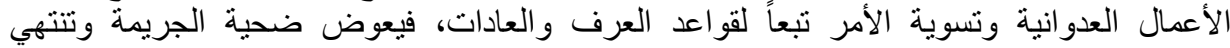

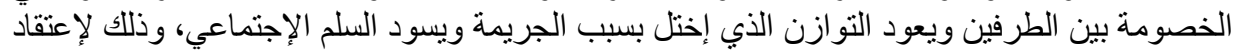

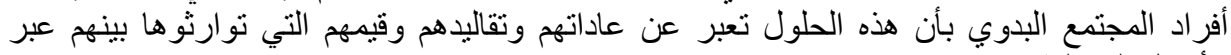

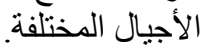

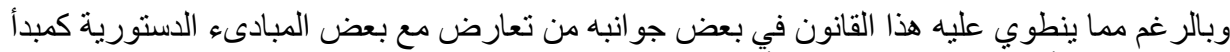

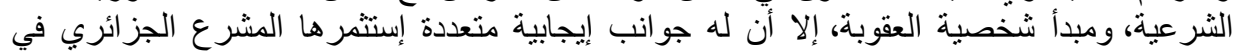

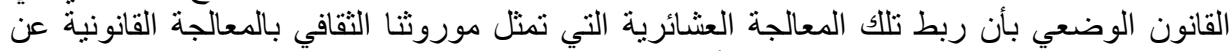

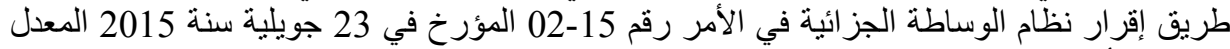

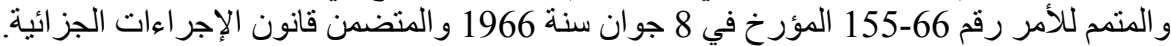

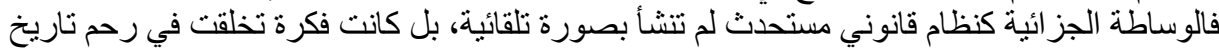

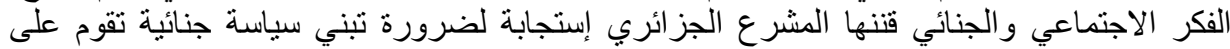
المصالحة بين أفر اد المجتمع الأني

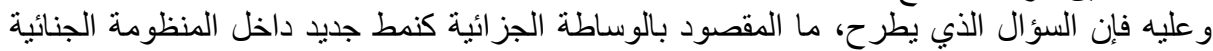

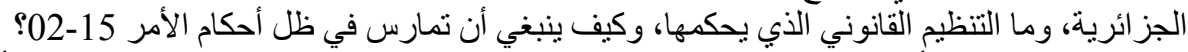

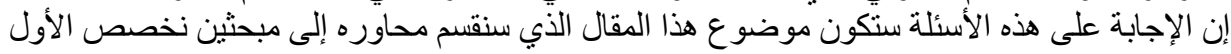

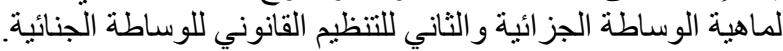

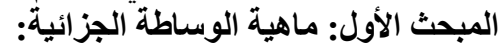

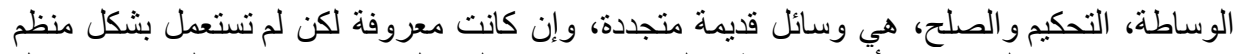

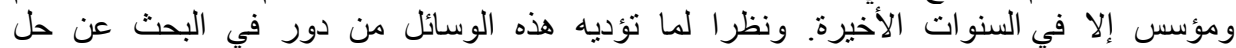

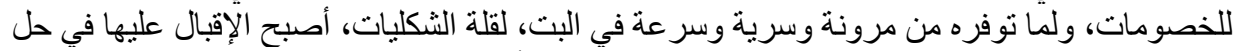

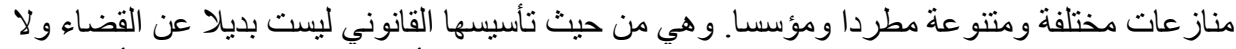

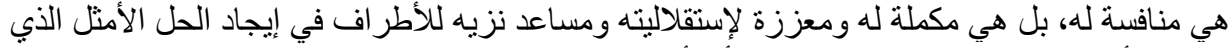

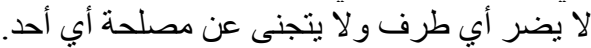

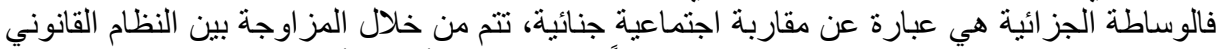

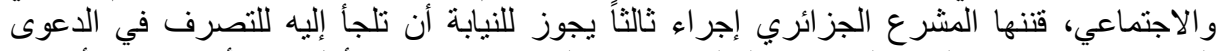

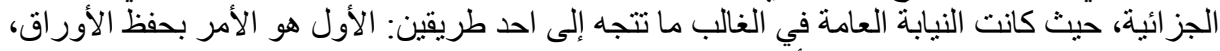

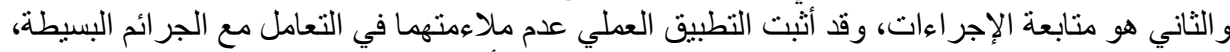

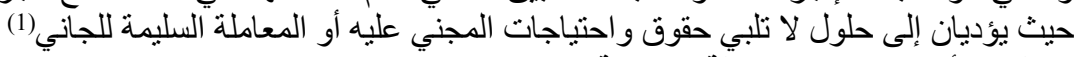
المطلب الأول: مفهوم الوساطة الجزئ الجزائية:

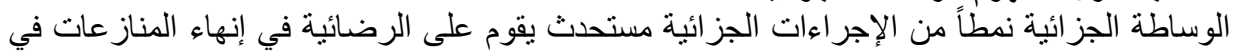

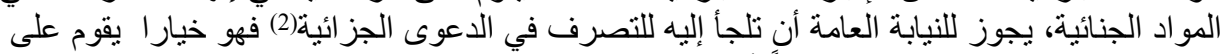

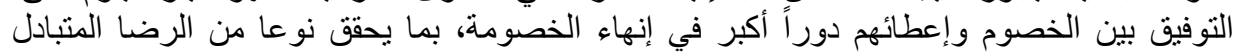

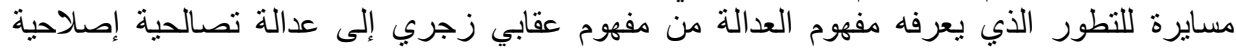

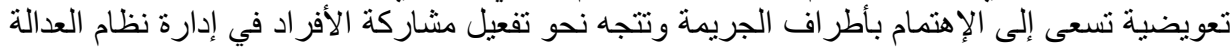

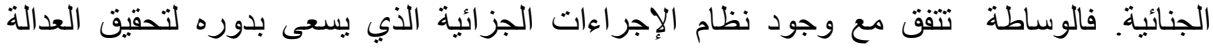

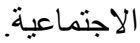

كما أن هذا النمط الإجر ائي يمثل أحد الحلول الإجرائية لتقليص الكم الهائل والمستمر في أعداد القضايا

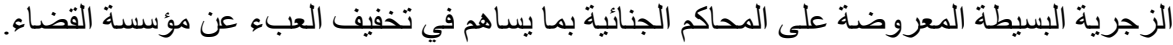




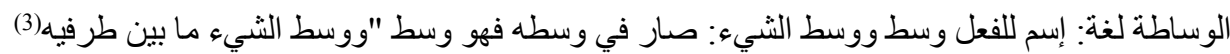

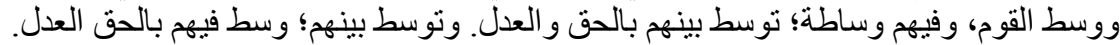

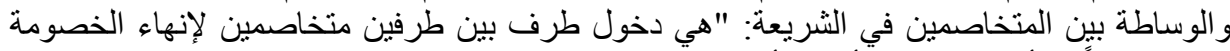

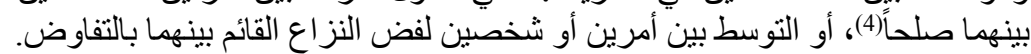

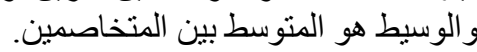

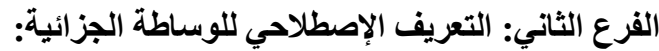

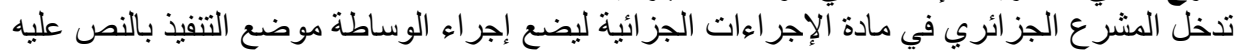

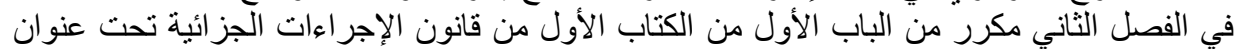

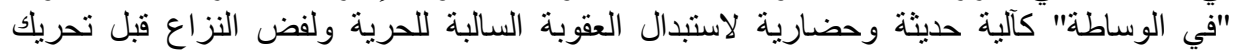

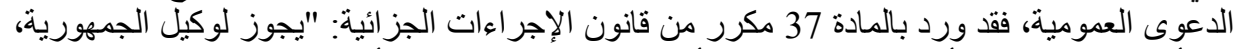

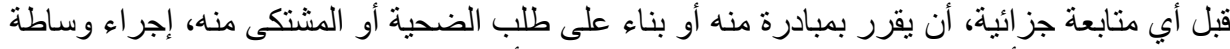

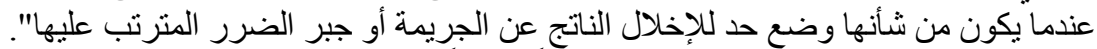

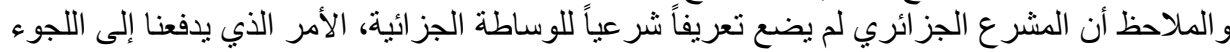

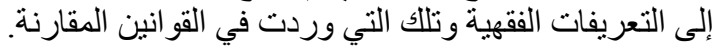

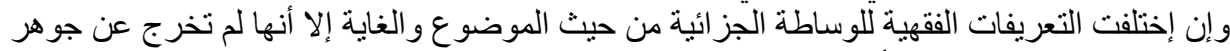

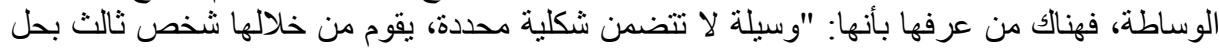

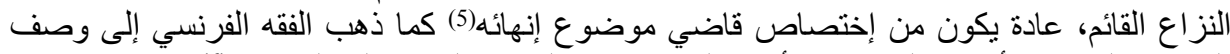

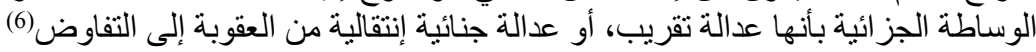

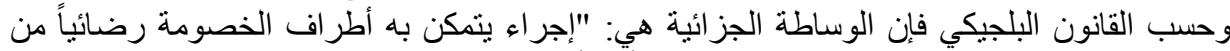

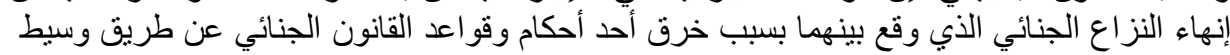

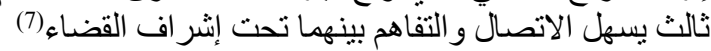

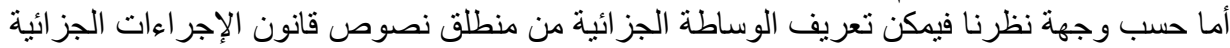

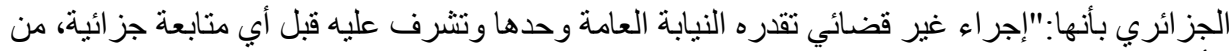
شأنه جبر الضرر ووضع حد للإخلانل الناتج عن الجريمة ذات الخطورة البرة البسيطة".

المطلب الثاني: مبررات الوساطة الجزائية:

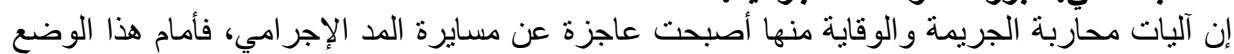

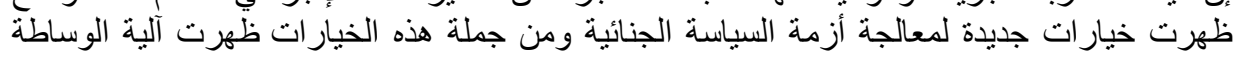

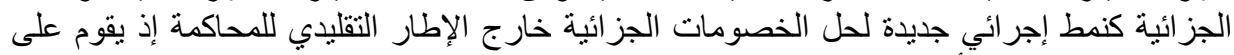

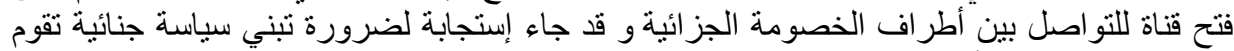

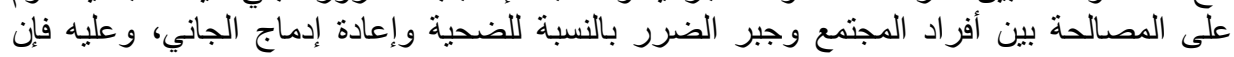

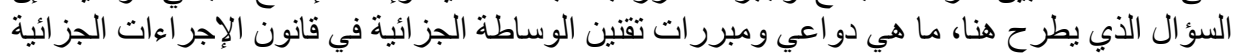

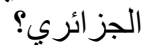
إن الدواعي و المبررات التي دعت إلى تقنين الوساطة الجزائية متعددة ومختلفة، غير أنه يمكن إيجاز ها

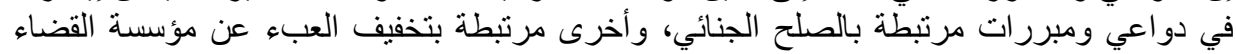
وبتفعيل العدالة التصالحية.

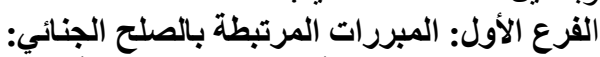

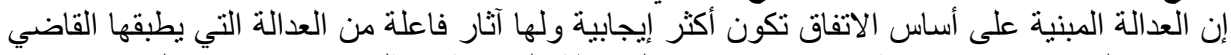

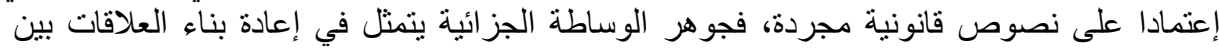

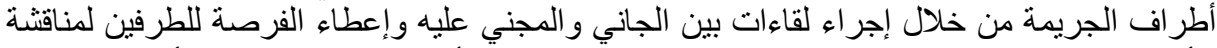

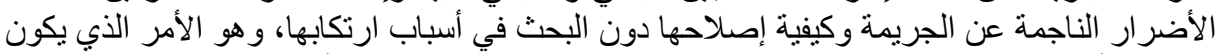

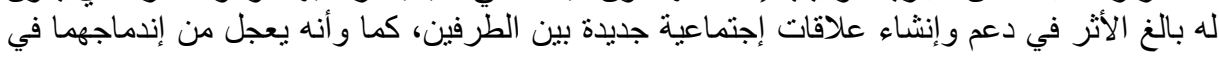


المجتمع، حيث يؤدي إلى جبر ضرر المجني عليه والقضاء على الثعور بالعزلة الإجتماعية التي تتناب

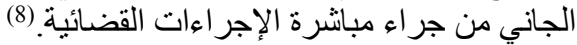

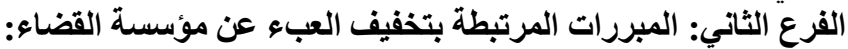

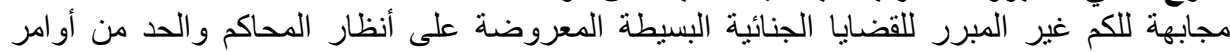

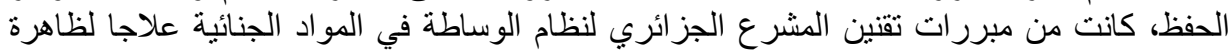

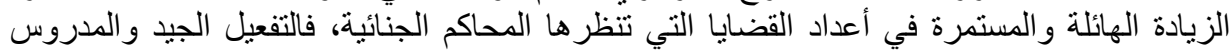

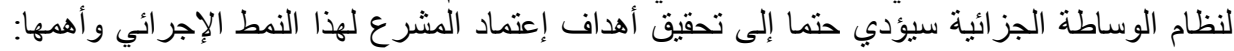

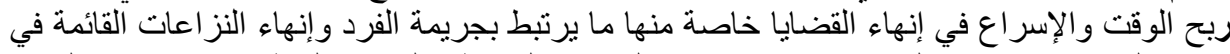

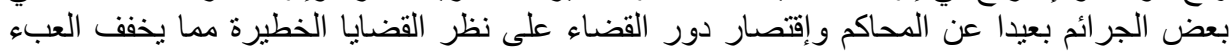
على المحاكم و السجون وخزينة الدولة.

المطلب الثالث: الطبيعة القانونية للوساطة الجزائية:

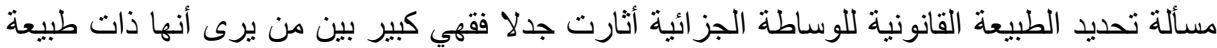

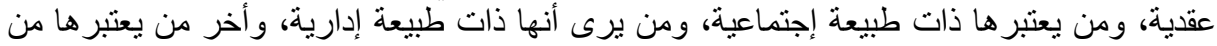

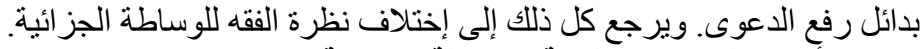
الفرع الأول: نظرة الفقه لطبيعة الوساطة الجزائية:

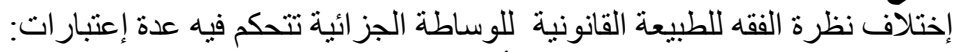

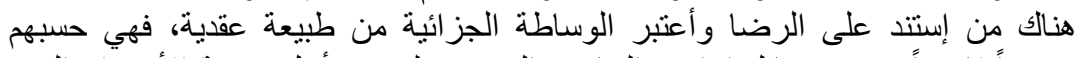

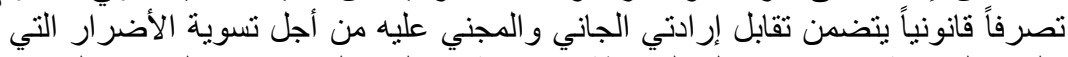

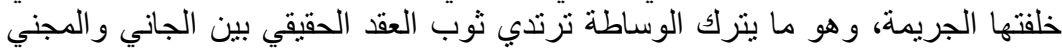

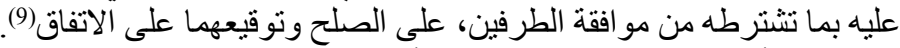

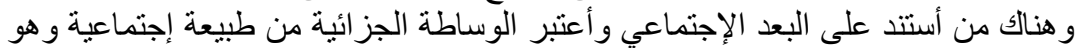

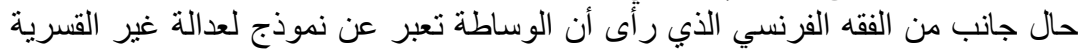

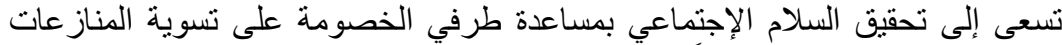

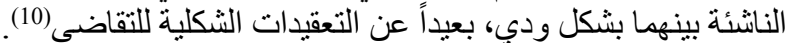

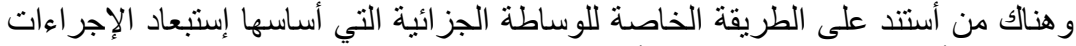

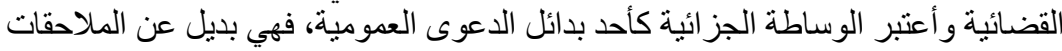

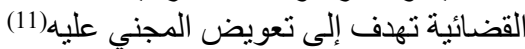

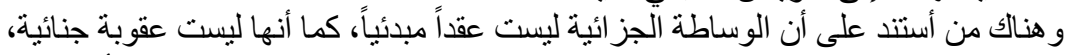

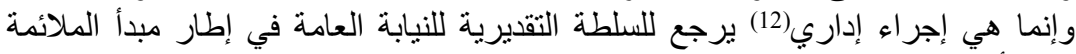

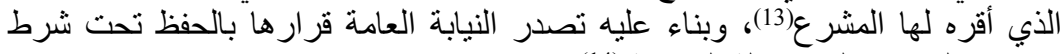

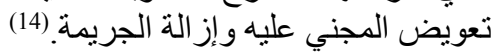

الفرع الثاني: طبيعة الوساطة الجزائية في التثريع الجزائري:

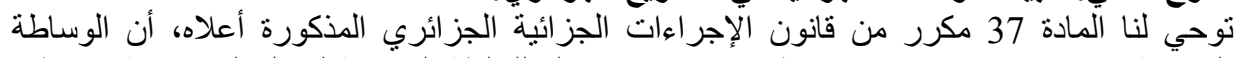

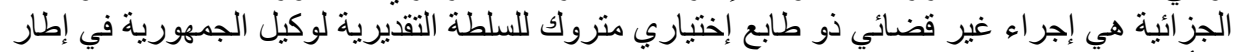

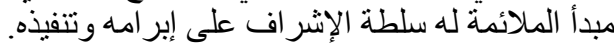

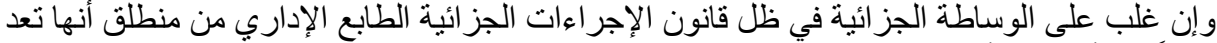

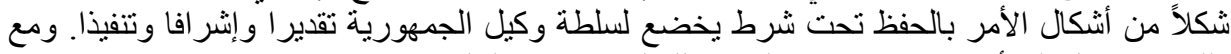

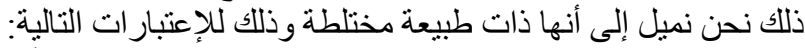

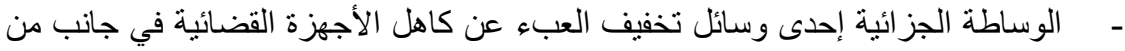
المناز عات الجنائية البسيطة، ومن ثم فإنها تعد من بدائل رفع الدعوى الجنائية. 
- - أن الوساطة تعد نموذجاً للتنظيم الاجتماعي، يتخذ من العدالة غير القسرية آلية لمساعدة

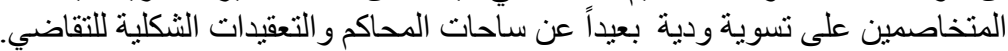
الهدف من الوساطة الوصول لإتفاق أو تنوية بودية ودية تنسم بطبيعة عقدية مدنية وجز ائية،

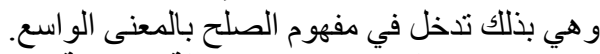

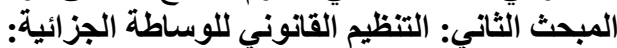

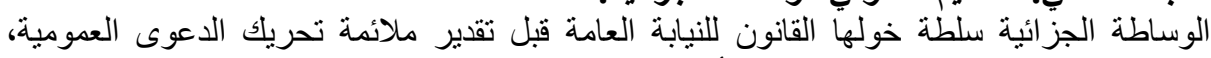

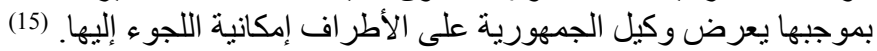

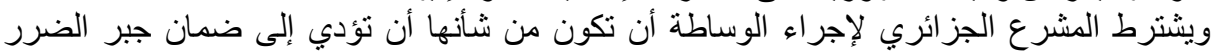

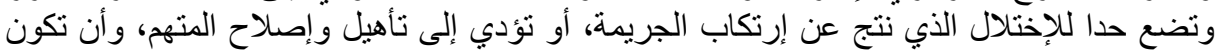

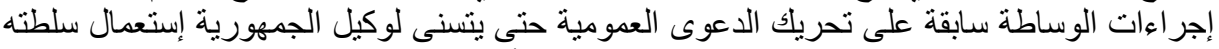

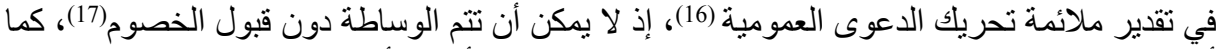

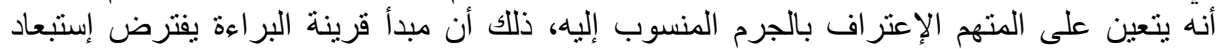

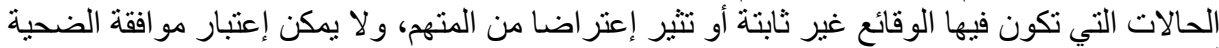

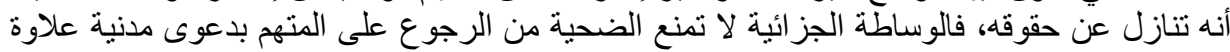

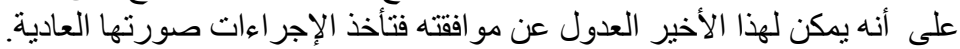

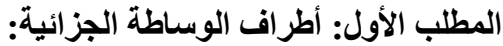

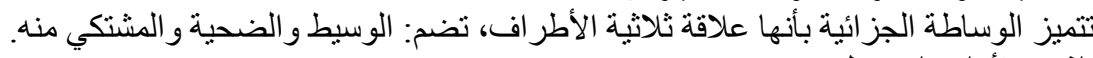

الفرع الأول: الوسيط الوسيط يعد الوسيط جوهر الاول عملية الوساطة وأحد أهم أطراف هذه العلاقة، كونه عنصراً مميزاً لها باعتباره

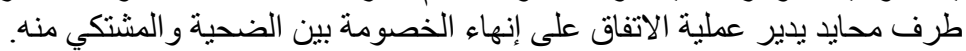
ولقد أعطى المشرع الجزائري الحق في التوسط في المواء التواد الجزائية لوكيل الجمهورية، لكن لماذا أسند

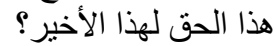
لعل ذلك يعود للإعتبار ات التالية:

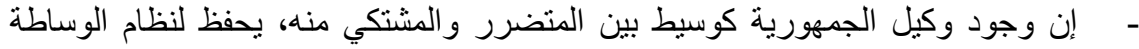
الصبغة الجزائية.

لأن الضرر الناتج هو بفعل مجرم قانونا، ووكيل الجمهورية يمثل النيابة العامة التي أوكل

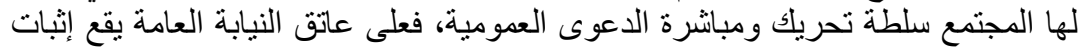
الجريمة.

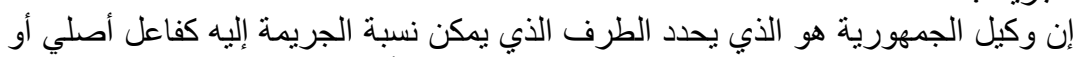

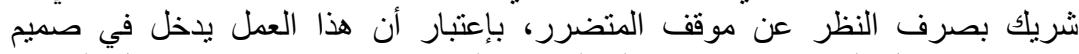

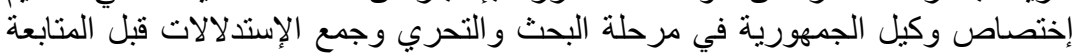

الجز ائية.

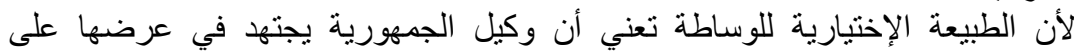

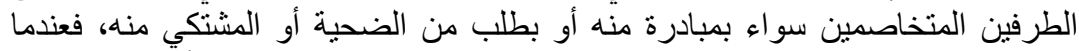

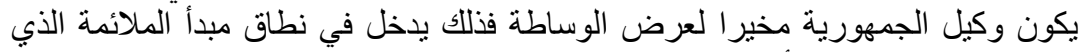

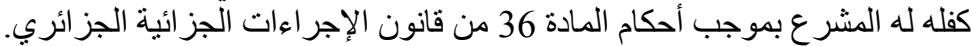

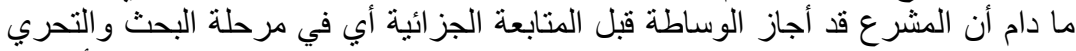

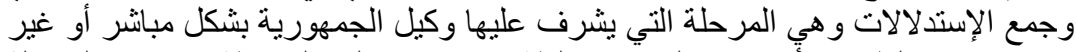
مباشر، فمن الطبيعي أُن يسند المشرع الإنس سلطة الإشراف على الوساطة في هذه المرحلة

بالذات إلى وكيل الجمهورية. الفرع الثاني: المشتكي منه: 
الواقع أن مصطلح المشتكي منه، الذب يثير إلى مرتكب الجريمة في مرحلة ما قبل تحريك الدعوى

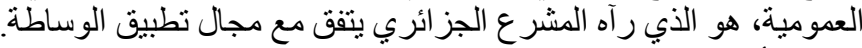

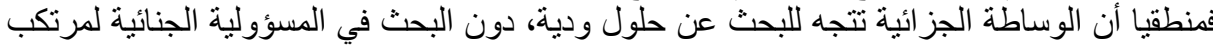

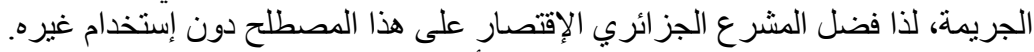

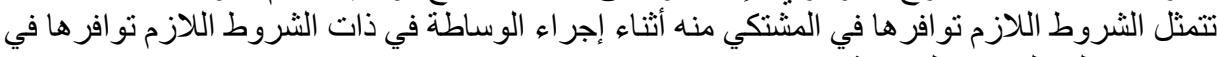
من ترفع عليه الدعوى الجز الئية.

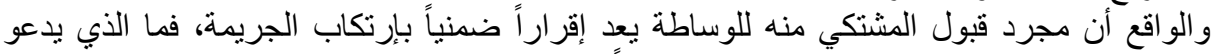

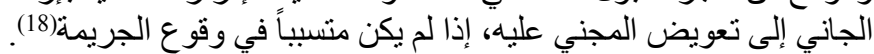
هذا والسؤال الذي يطرح، في ظل سكوت المشرع هل يمكن تطبيق إجراء الوساطة على المشتكي منه العائد؟

حسب إعتقادنا مادام أن من بين أهداف نظام الوساطة الجزائية هو إعادة تأهيل الجناة إجتماعيا، فمنطقيا

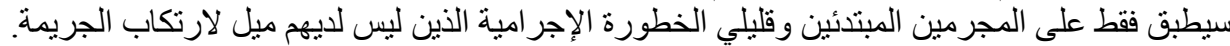

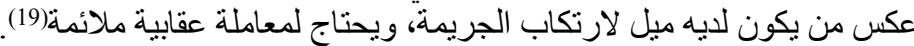

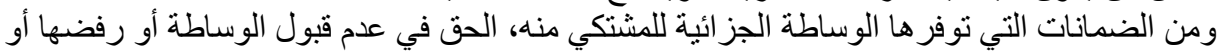

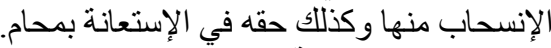

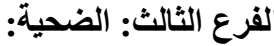

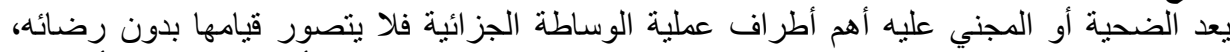

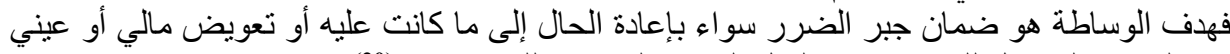

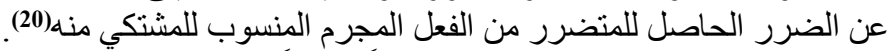

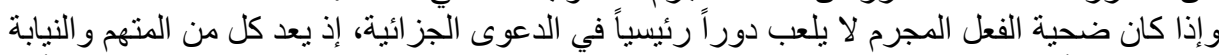

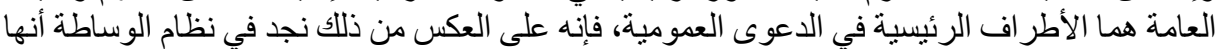

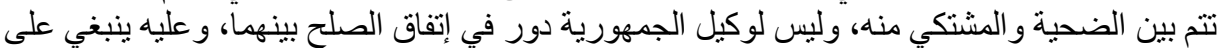

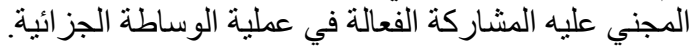

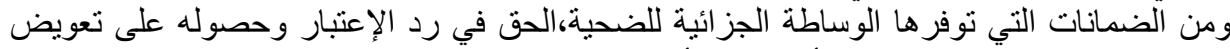

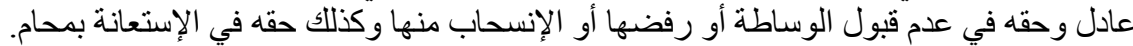
المطلب الثاني: شروط الوز الوساطة الجزائية:

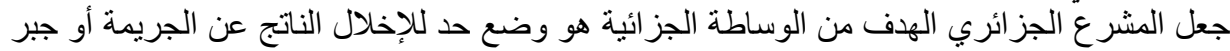

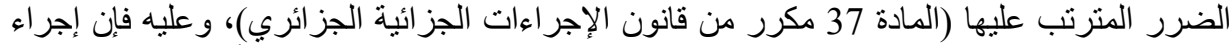

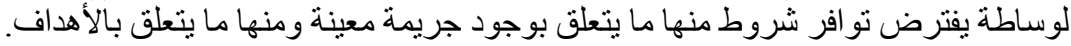

الفرع الأول: الثروط المترو الثقرة بوجود جريمة معينة:

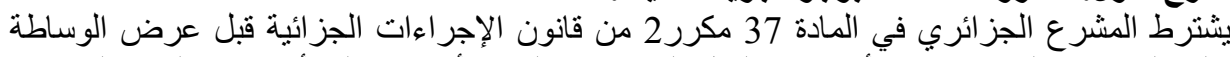

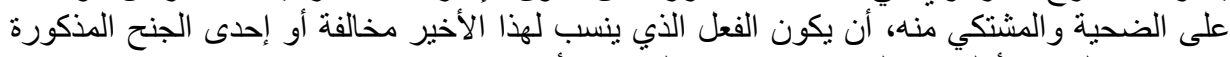

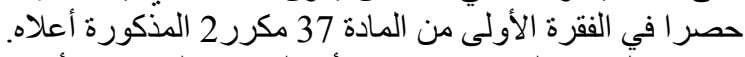

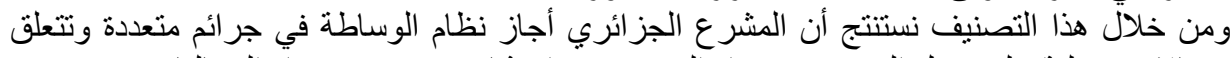

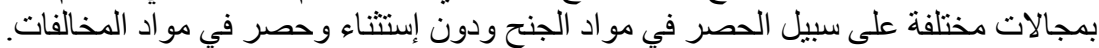

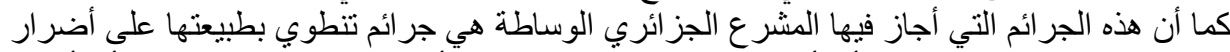
إما بدنية كالضرب والجرائ الجي أو أو أضرار مالية كالإستلاء على أموال الإلى الإرث قبل قسمتها أو أموال

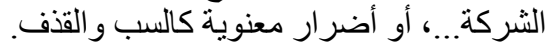

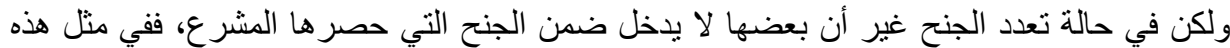

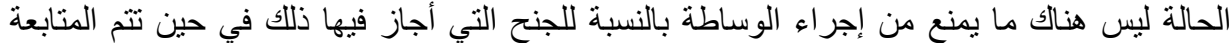


شرع نظام الوساطة لتحقيق أهداف معينة وهي المنصوص عليها في المادة 37 مكرر من قانون

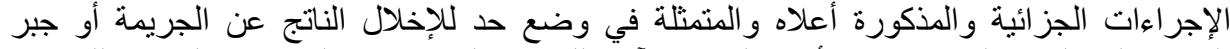

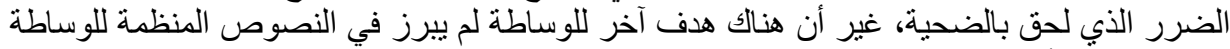
الجز ائية و هو تأهيل وإعادة إدماج المشتكي منه مرتكب الن الجريمة.

الفقرة الأولى: وضع حد للإخلال الناتج عن الجريمة:

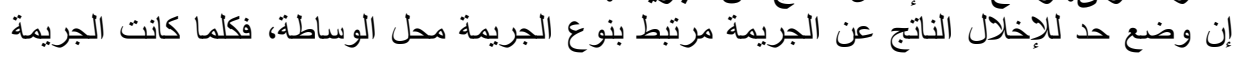

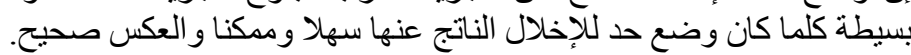

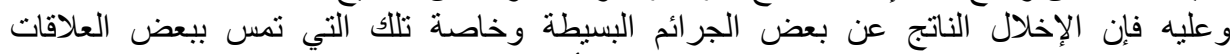

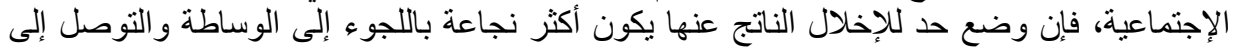

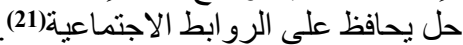
الفقرة الثانية: جبر الضرر المترتب على التئل الجريمة:

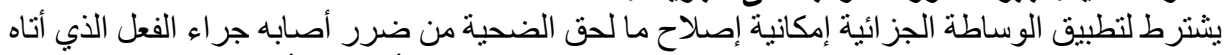

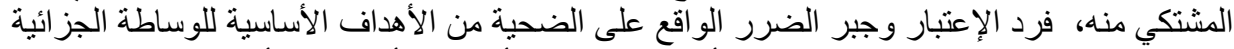

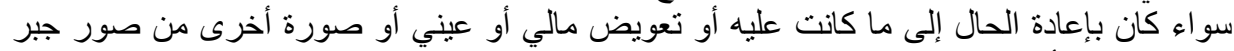

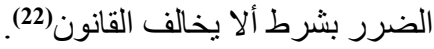

الفقرة الثالثة: تأهيل وإعادة إدماج المشتيكي منه مرتكب الجريمة:

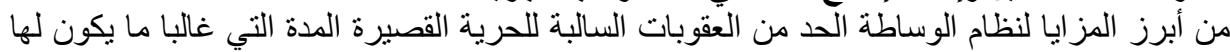

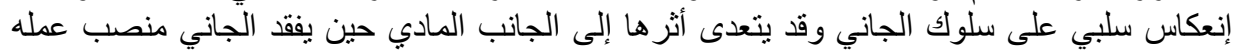

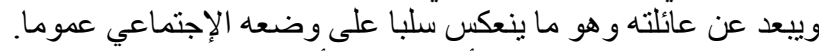

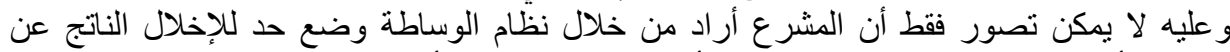

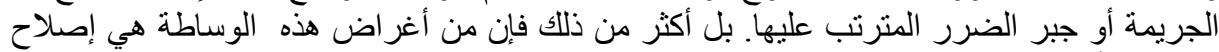

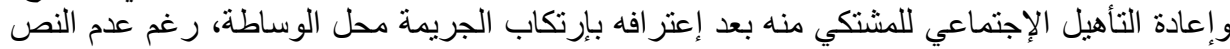

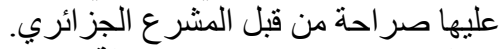

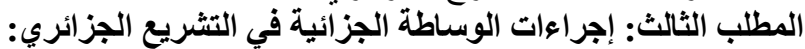

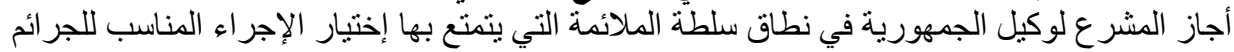

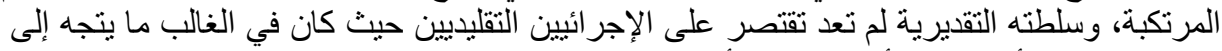

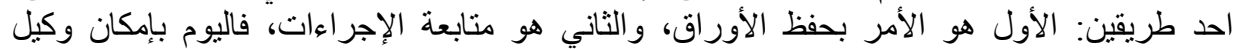

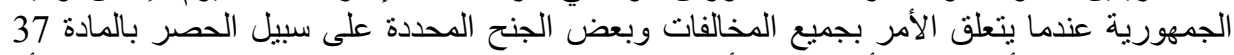

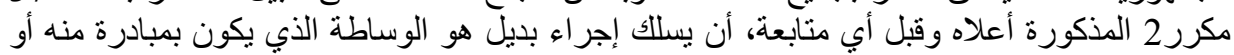

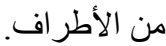
وتتم إجر اءات الوساطة الجزائية عبر مراحل ترتب أثار سنتناولها على النحو التالي: الفرع الأول: مراحل إجراءاءت الواتل الوساطة الجزائية:

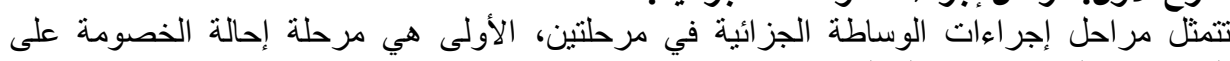

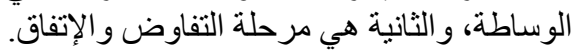

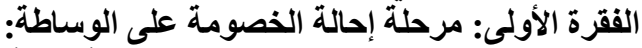

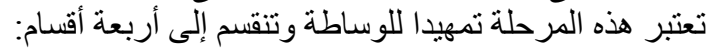

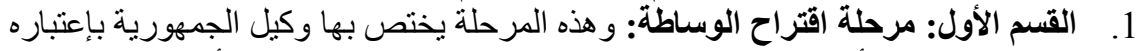

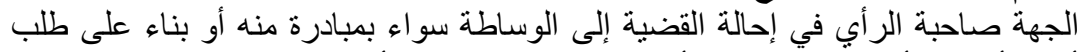

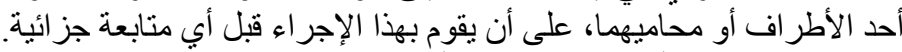

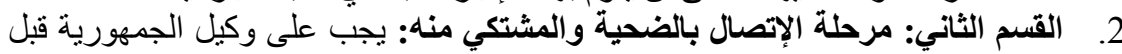

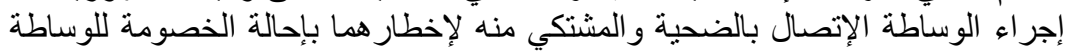


و الحصول على قبولهما لإجر ائها.وما يؤاخذ على المشر ع الجزائري أنه تغاضى عن تحديد

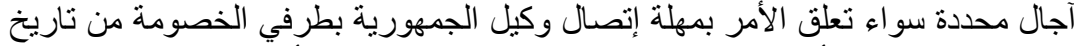

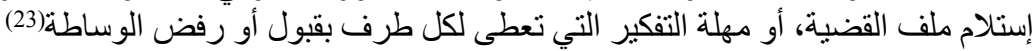

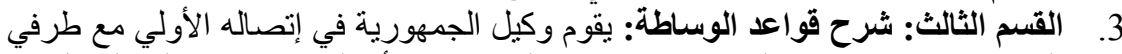

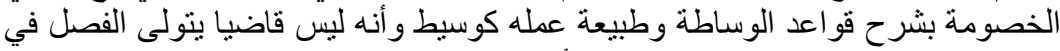

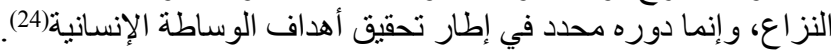

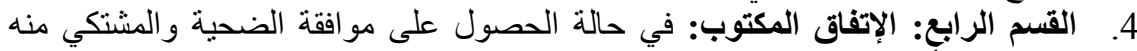

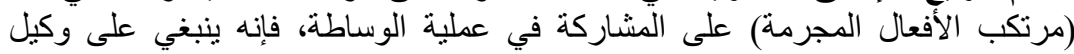

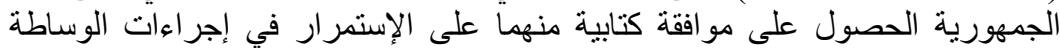

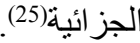

الفقرة الثانية: مرحلة التفاوض والإتفاق:

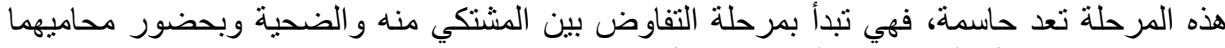

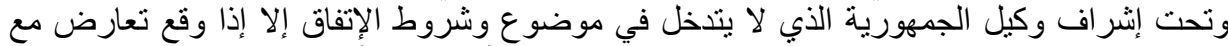

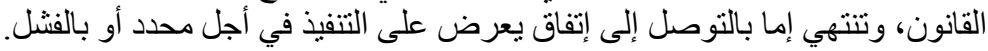

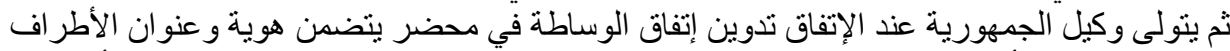

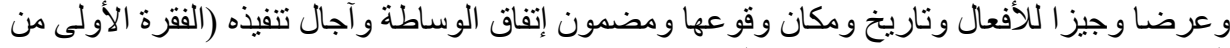

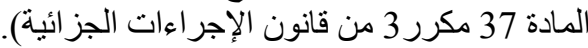

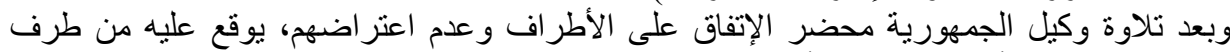

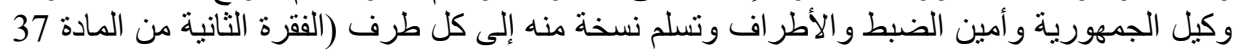

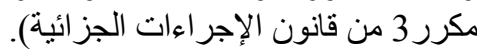

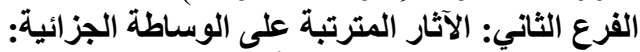

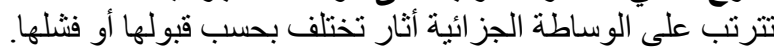

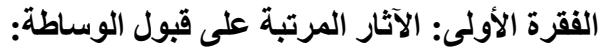

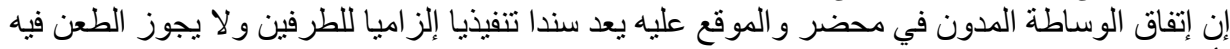

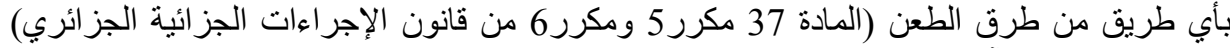

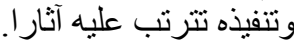

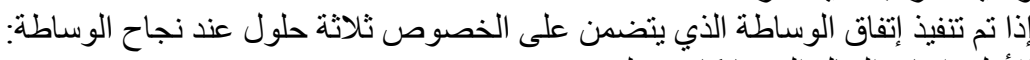

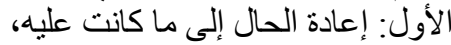

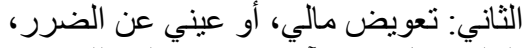

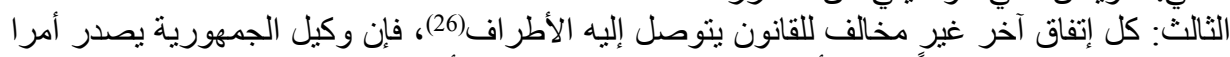

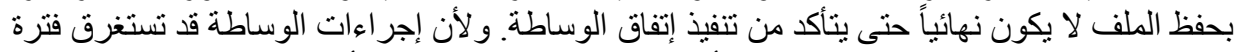

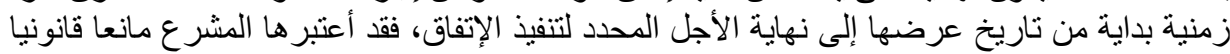
يوقف سريان تقادم الدعوى العمومية (المادة 37 مكرر 7 من قانون الإجراءات الإن الجز ائية الجز ائري). 


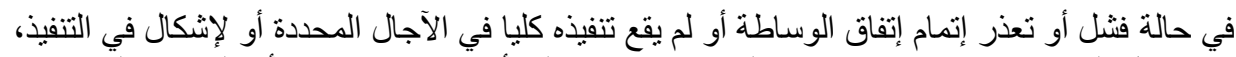

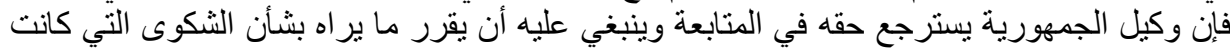

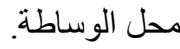

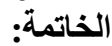

نجاح تجربة ركوب قاطرة الحلول البديلة خاصة منها الوساطة في المو اد الجزائية في الجرائم الجئي

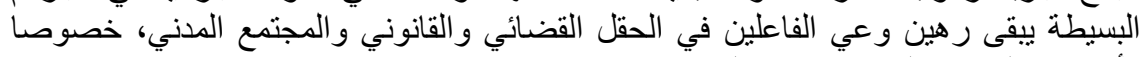

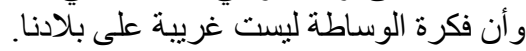

فأمام مشكلة بطء الإجر اءات الجز ائية التي تعرقل حسنيات حسن سير العدالة الجنائية لكون العدالة البطيئة

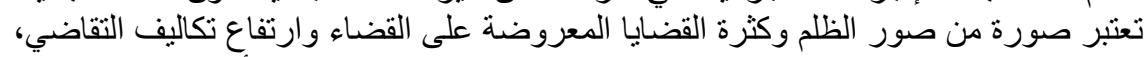

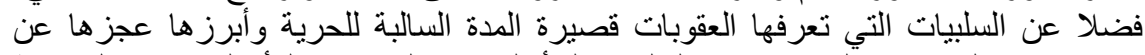

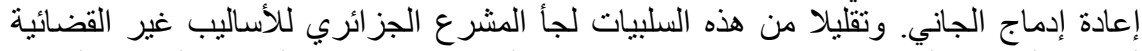

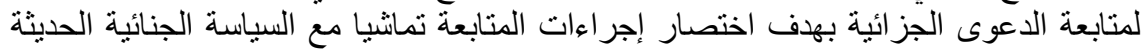

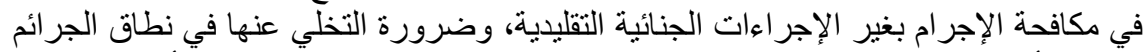

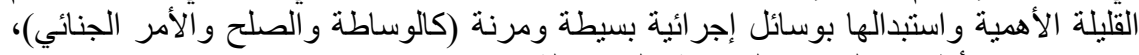
ركيزتها رضا أطر اف الدعوى الجز ائية على وسيلة إنهائها.

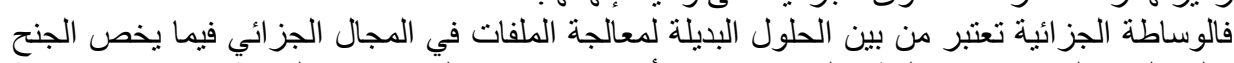

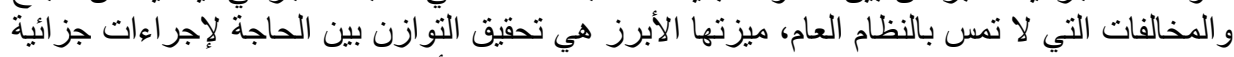

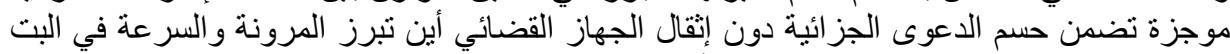

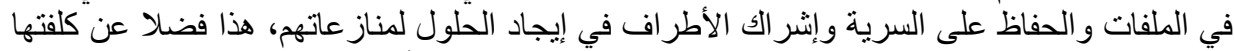

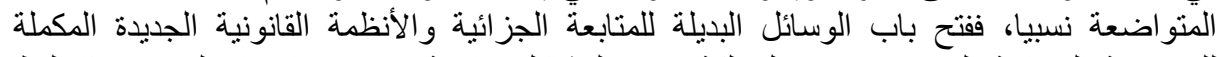

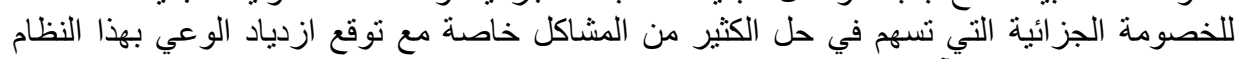

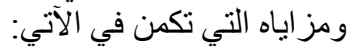

1 1. يشكل لبنة جديدة تضاف إلى المنظومة الجز ائية.

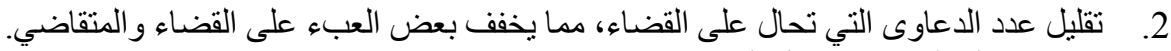
3. 4. - كنام أقرب إلى الواقع من القضاء.

5. يكفل هذا النظام محافظة طرفي الخصومة النطاء على خصوصية النزاع القائم بينهما مما يساهم في المحافظة على الرو ابط الاجتماعية.

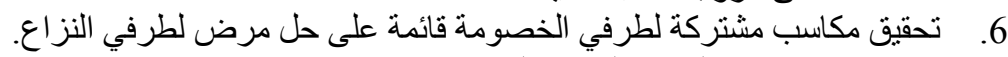
7.

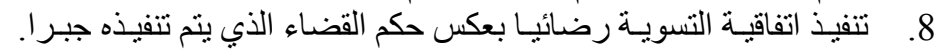

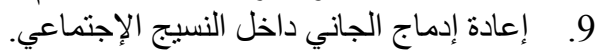

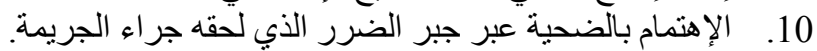

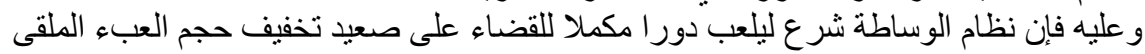

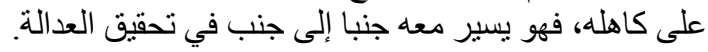




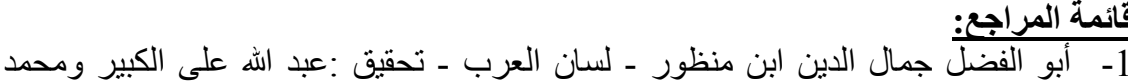

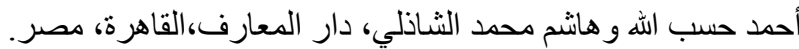

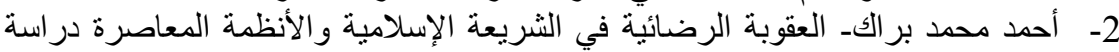

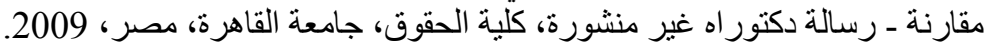

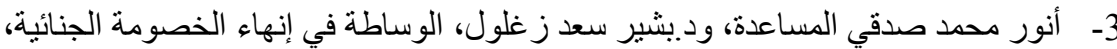

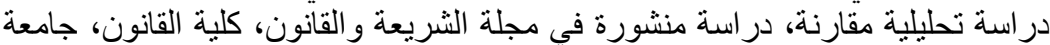

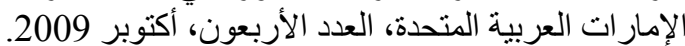

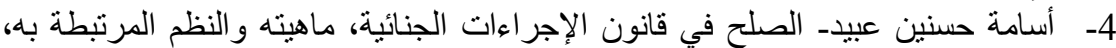

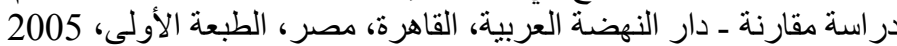

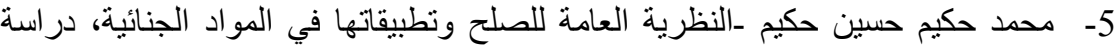

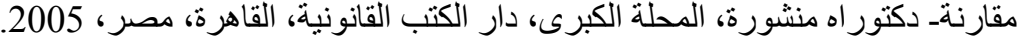

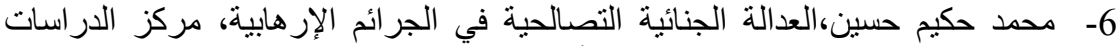

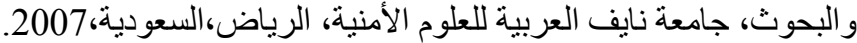

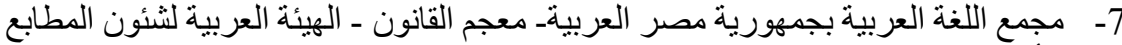

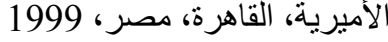

8- رامي متولي القاضي- الوساطة في القانون الجنائي الإجرائي المقارن- دار النهضة النئة العربية، القاهرة، مصر، الطبعة الأولى، 2010

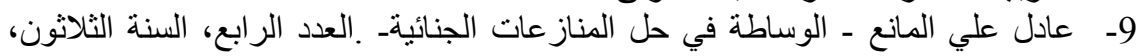
مجلة الحقوق، جامعة الكويت، الكويت 2006

10- عمر محمد سالم ـ نحو تيسير الإجراءات الجعة الجنائيةـ دار النهضة العربية، القاهرة، مصر

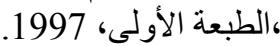

11- هثام مفضي المجالي- الوساطة الجزائية وسيلة غير تقليدية في حل النزائة اعات الجنائية

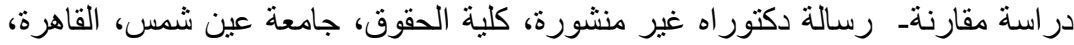
مصر، 2008

12- فايز عابد الظفيري، تأويلات في الوساطة الجزائية بوصفها وسيلة لإنهاء الدعوى الجزائية، إنهاء

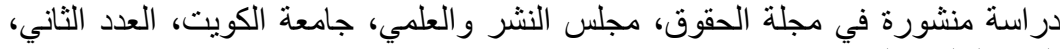

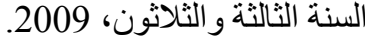

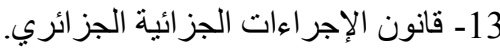

14- Delmas -Marty (M.), les grands systèmes de politique criminelle, puff, coll., Thémis, paris, 1992.

15- Blanc (G.), La médiation pénale (commentaire de l'article de 6 de la loi no 93-2 du 4 janvier 1993, portant reforme de la procédure pénale) J.C.P. (semaine juridique) 1994, no. 3760.

16- Roets: L'impartialité et justice pénale, préface de Pradel.

justice réparatrice et médiation : convergences et divergences. Edit. Jacou, M.

L'harmattan; collection sci 
(1) عمر محمد سالم ـ نحو تيسير الإجراءات الجنائية ـ دار النهضة العربية، القاهرة، مصر ، الطبعة

الأولى، (1) 1997، صع: صدم: 118.

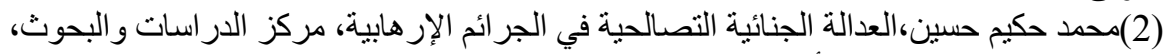

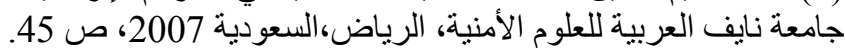

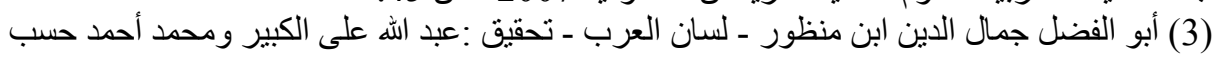

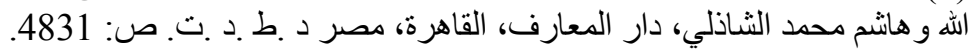

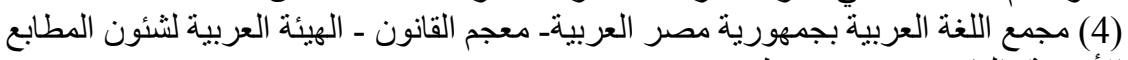

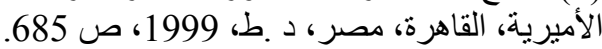

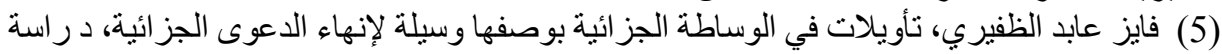

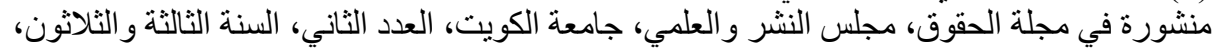

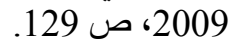

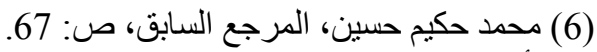

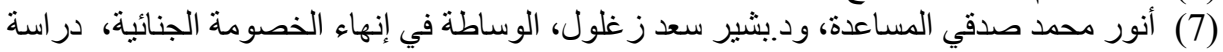

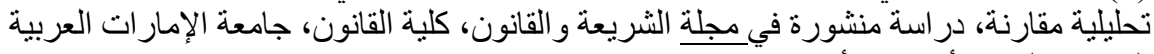

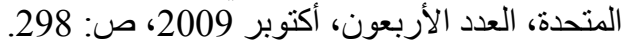

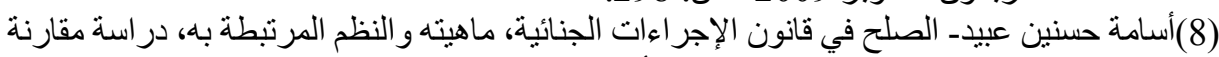

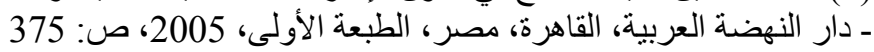

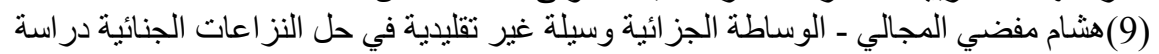

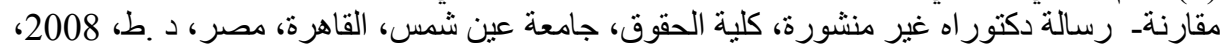
ص: 98

(10) أحمد محمد بر الكـ العقوبة الرضائية في الثريعة الإسلامية و الأنظمة المعاصرة در اسة مقارنة ـ

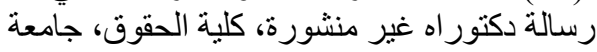

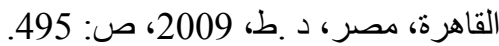

(11) رامي منولي القاضي-الوساطة في القانون الجنائي الإجر ائي المقارنـ دار القار النهضة العربية،

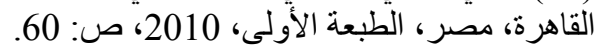

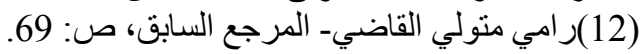

(13)Roets: L'impartialité et justice pénale, préface de Pradel. P: 307.

(14)Delmas -Marty (M.), les grands systèmes de politique criminelle, puff, coll., Thémis, paris, 1992. P:162.

(15) محمد حكيم حسين حكيم ـالنظرية العامة للصلح وتطبيقاتها في المو اد الجنائية، در اسة مقارنة.

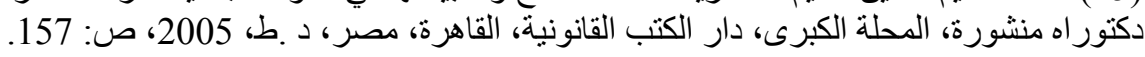
(16) BLANC Gérard: La médiation pénale (commentaire de l'article de 6 de la loi no 93-2 du 4 janvier 1993, portant reforme de la procédure pénale) J.C.P. (semaine juridique) 1994, no. 3760, P 211-215.

(17) BLANC Gérard, op cit, P 211-215.

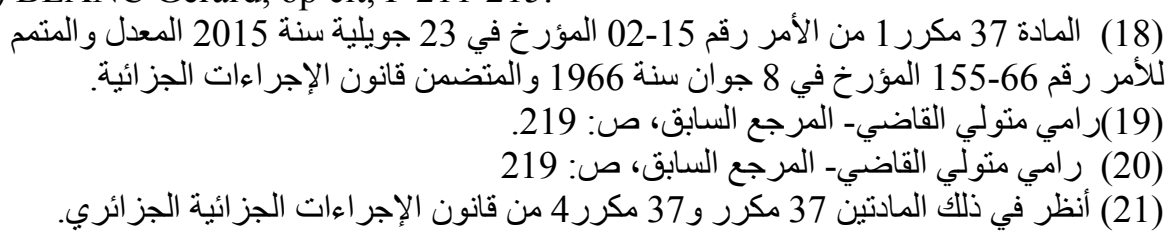


(22)M. Jacou, justice réparatrice et médiation : convergences et divergences.

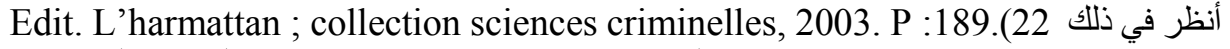

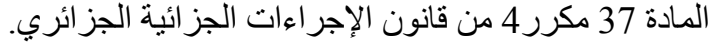

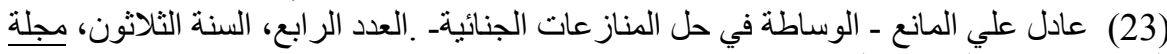

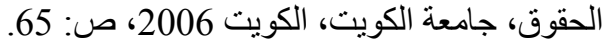

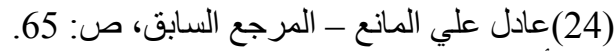

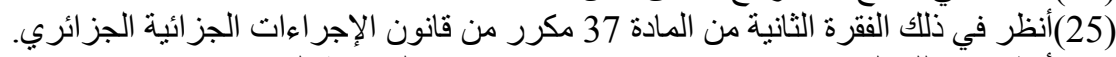

(26)انظر في ذلك المادة 37 مكرر4 من قانون الإنجر الاءدات الجز ائية الجزائري. 